\title{
Perov multivalued contraction pair in rectangular cone metric spaces
}

\author{
M. Abbas ${ }^{1,2}$, V. Rakočević $\tilde{c}^{3}, Z$. Noor ${ }^{1}$ \\ 1 Department of Mathematics, Government College University, \\ Lahore, 54000, Pakistan \\ 2 Department of Mathematics and Applied Mathematics, University of Pretoria, \\ Pretoria, 0002, South Africa \\ 3 Faculty of Sciences and Mathematics, Department of Mathematics, University of Niš, \\ Niš, 18000, Serbia
}

For citation: Abbas M., Rakočević V., Noor Z. Perov multivalued contraction pair in rectangular cone metric spaces. Vestnik of Saint Petersburg University. Mathematics. Mechanics. Astronomy, 2021, vol. 8 (66), issue 3, pp. 484-501. https://doi.org/10.21638/spbu01.2021.310

Perov studied the Banach contraction principle in the framework of a generalized metric space and presented Perov contraction condition where the contractive constant is replaced by a matrix with nonnegative entries and spectral radius less than 1. Azam et al. presented the notion of rectangular cone metric space following the idea of Branciari, Huang and Zhang by replacing the triangular inequality in the cone metric space by rectangular inequality. Motivated by the work of Abbas and Vetro and Radenović, the purpose of this paper is to introduce a new class of Perov type multivalued mappings and present a common fixed point result for such mappings on a complete rectangular cone metric space. Furthermore, an example is also presented to demonstrate the validity of our results. Our results extend, unify and generalize various comparable results in the existing literature.

Keywords: fixed point, cone metric space, rectangular metric space.

1. Introduction. Let $(X, d)$ be a metric space. A mapping $T: X \rightarrow X$ is called a contraction if there exists a constant $k \in[0,1)$ such that for any $x, y \in X$, we have $d(T x, T y) \leq k d(x, y)$. The famous Banach contraction theorem [1] states that a contraction mapping on a complete metric space has a unique fixed point, that is, there exists a point $x$ in $X$ such that $x=T x$. The set of all fixed point of $T$ is denoted by $\operatorname{Fix}(T)$. Banach contraction principle and its variants have various applications in many areas of mathematics and related disciplines such as differential equations, optimization theory, computer science, economics and telecommunication (see, e.g., [2]). This intrigued several mathematicians to extend Banach contraction theorem to different directions. One such way is to extend the domain of a mapping.

Branciari [3] gave the notion of rectangular metric spaces by replacing the triangular inequality, that is, $d(x, y) \leq d(x, z)+d(z, y)$ for $x, y, z$ in $X$ by a rectangular inequality, i. e., $d(x, y) \leq d(x, u)+d(u, w)+d(w, y)$ for any $x, y, z, w$ in $X, u \neq v$ and $u, v \in X \backslash\{x, y\}$. Since then, many authors have established various fixed point theorems in rectangular metric spaces. For more results in this direction under different contractive conditions, we refer to [4-10]. In an ordinary metric space $X$, for any two points in an abstract set $X$, there is a positive real number that measures the distance between them. On the other hand, if $X$ is an arbitrary set and the set $\mathbb{R}^{+}$is replaced with a set $E$ equipped with

(c) St. Petersburg State University, 2021 
some order structure, whereas the distance mapping $d: X \times X \rightarrow E$ satisfies properties analogous to the conditions of ordinary metric $d: X \times X \rightarrow \mathbb{R}^{+}$, then the notion of a metric can be extended in several ways. For example, if $E=\mathbb{C}$ the set of all complex numbers, then we have the concept of a complex valued metric space [11], if $E=\mathbb{R}^{n}$, we have the notion of a generalized metric space. If $E$ is a topological vector space, we obtain the vector-valued metric space [12]. If $E$ is a $C^{*}$-algebra, then we obtain the $C^{*}$ algebra valued metric space [13]. Later, the concept of K-metric spaces was introduced by taking $E$ as a real Banach space [14]. In 2007, Huang and Zhang [15] rediscovered the notion of K-metric space under the name cone metric space. The reader interested in fixed and common fixed point results in the setup of cone metric spaces is referred to [16-18].

In 1964, Perov [19] studied the Banach contraction principle in the framework of a generalized metric space and presented Perov contraction condition where the contractive constant is replaced by a matrix with nonnegative entries and spectral radius less than 1 . He also obtained some fixed point theorems with various applications in coincidence problems, coupled fixed point problems and systems of semilinear differential inclusions $[19,20]$. It must be noted that this generalized metric space is a special case of a normal cone metric space. Azam et al. [21] presented the notion of rectangular cone metric space following the idea of Branciari and Huang and Zhang by replacing the triangular inequality in the cone metric space by rectangular inequality. They also studied the fixed point results for both Banach and Perov type contractions in rectangular cone metric spaces. Shukla et al. [22] proved a generalized Banach fixed point theorem for the setting of cone rectangular Banach algebra valued metric spaces.

Recently, Radenović and Vetro [23] introduced the notion of Sehgal - Guseman Perov type mappings and established a result of existence and uniqueness of fixed points for this class of mappings. Vetro and Radenović [24] studied fixed point results under various Perov type contractive conditions in rectangular cone metric spaces. Markin [25] initiated the study of fixed points for multivalued contractions and nonexpansive maps using the Hausdorff metric. He also developed an interesting and rich fixed point theory for multivalued maps having applications in control theory, convex optimization, differential inclusions and economics. The concept of multivalued contractions was initiated by Nadler [26]. He showed that a multivalued contraction possesses a fixed point in a complete metric space. Later several generalizations of Nadler's fixed point theorem were obtained (see, [27, 28]).

Latif and Beg [29] extended Kannan mappings to multivalued mappings and introduced the notion of a K-multivalued mapping. The term R-multivalued mapping as a generalization of K-multivalued mapping was presented by Rus [30]. Abbas and Rhoades [31] introduced the notion of a generalized R-multivalued mappings and established common fixed point results for such mappings. Recently, in 2020 Altun and Olgun [32] have introduced the concept of $F$-contraction on vector-valued metric space. Then they proved a fixed point result that includes the famous Perov fixed point theorem as properly. They provided a nontrivial and illustrative example showing this fact.

Motivated by the work of Abbas et al. [33] and Vetro and Radenović [24], the purpose of this paper is to introduce a new class of Perov type multivalued mappings and present a common fixed point result for such mappings on a complete rectangular cone metric space. Furthermore, an example is also presented to demonstrate the validity of our results. Our results extend, unify and generalize various comparable results in the existing literature $[3-5,34]$ and $[6]$. 
2. Preliminaries. Let $E$ be a real Banach space. A subset $P$ of $E$ is called a cone if and only if:

1) $P$ is nonempty, closed and $P \neq\{\theta\}$ (where $\theta$ is the zero element of $E$ );

2) $a, b \in \mathbb{R}, a, b \geq 0$ and $x, y \in P$ implies that $a x+b y \in P$;

3) $P \cap(-P)=\{\theta\}$.

Partial ordering on $E$ is defined with help of a cone $P$ as follows: $x \preceq y$ if and only if $y-x \in P$. We shall write $x \prec y$ to indicate that $x \preceq y$ but $x \neq y$ and $x \ll y$ stands for $y-x \in i n t P$, where $i n t P$ denotes the interior of $P$. A cone $P$ is normal or semi monotone if

$$
\inf \{\|x+y\|: x, y \in P \text { and }\|x\|=\|y\|=1\}>0
$$

or equivalently, if there is a number $K>0$ such that for all $x, y \in P, 0 \preceq x \preceq y$ implies that $\|x\| \leq K\|y\|$. The least positive number satisfying the above inequality is called a normal constant of $P$. If $x=\left(x_{1}, x_{2}, \ldots, x_{n}\right)^{T}, y=\left(y_{1}, y_{2}, \ldots y_{n}\right)^{T} \in$ $\mathbb{R}^{n}$, then $a \preceq b$ means that $a_{i} \leq b_{i}, i=1, \ldots, n$. In this case, the set $P=$ $\left\{x=\left(x_{1}, \ldots, x_{n}\right)^{T} \in \mathbb{R}^{n}: x_{i} \geq 0\right.$ for $\left.i=1,2, \ldots, n\right\}$ is a normal cone with the normal constant $K=1$. A cone $P$ is called solid if it has a nonempty interior i. e. int $P \neq \emptyset$.

Definition 2.1. Let $X$ be a nonempty set. A mapping $d: X \times X \rightarrow E$ is said to be a cone metric on $X$ if for any $x, y, z \in X$, the following conditions hold:

1) $\theta \preceq d(x, y)$ for all $x, y \in X$ and $d(x, y)=\theta$ if and only if $x=y$;

2) $d(x, y)=d(y, x)$;

3) $d(x, y) \preceq d(x, z)+d(z, y)$.

The pair $(X, d)$ is called a cone metric space. If $E=\mathbb{R}^{n}$, then a nonempty set $X$ with a vector valued metric $d$ is called a generalized metric. The concept of a cone metric space is more general than that of a metric space.

Lemma 2.2 [35]. Let $(X, d)$ be a cone metric space over a cone $P$ in $E$. Then one has the following:

(i) int $P+\operatorname{int} P \subseteq \operatorname{int} P$ and $\mu$ int $P \subseteq$ int $P, \mu>0$;

(ii) for any given $c \gg 0$ and $c_{0} \gg 0$, there exists $n_{0} \in \mathbb{N}$ such that $\frac{c_{0}}{n_{0}} \ll c$;

(iii) if $a_{n}, b_{n}$ are sequences in $E$ such that $a_{n} \rightarrow a, b_{n} \rightarrow b$ and $a_{n} \preceq b_{n}$ for all $n \geq 1$, then $a \preceq b$.

The following is a crucial result.

Lemma 2.3 [36]. Let $(X, d)$ be a cone metric space. Then for each $c \in E$ with $c \gg 0$, there exists $\sigma>0$ such that $(c-x) \in \operatorname{IntP}($ i.e. $x \ll c)$ whenever $\|x\|<\sigma, x \in E$.

Definition 2.4. Let $X$ be a nonempty set. A mapping $d: X \times X \rightarrow E$ is called a rectangular cone metric on $X$ if it satisfies the following conditions:

(b1) $d(u, v) \succeq \theta$ for all $u, v \in X$ and $d(u, v)=\theta$ if and only if $u=v$; 
(b2) $d(u, v)=d(v, u)$ for all $u, v \in X$;

(b3) $d(u, v) \preceq d(u, z)+d(z, w)+d(w, v)$ for all $u, v \in X$ and for all distinct points $w, z \in X \backslash\{u, v\}$.

Then the pair $(X, d)$ is called a rectangular cone metric space over cone $P$.

Definition 2.5. Let $(X, d)$ be a rectangular cone metric space over a solid cone $P$ and $\left\{u_{n}\right\}$ a sequence in $X$. We say that

(I) $\left\{u_{n}\right\}$ is a Cauchy sequence if for every $c \in E$ with $c \gg \theta$, there is an $n(c) \in \mathbb{N}$ such that for all $n, m \geq n(c), d\left(u_{n}, u_{m}\right) \ll c$;

(II) $\left\{u_{n}\right\}$ is a convergent sequence if for every $c \in E$ with $c \gg \theta$, there is an $n(c) \in \mathbb{N}$ such that for all $n \geq n(c), d\left(u_{n}, u\right) \ll c$ for some $u \in X$.

If the sequence $\left\{u_{n}\right\}$ converges to $u$, we denote $u_{n} \underset{c}{\rightarrow} u$. A cone metric space $X$ is said to be complete if every Cauchy sequence in $X$ is convergent in $X$.

If $P$ is a normal solid cone, then $u_{n} \stackrel{c}{\rightarrow} u$ if and only if $d\left(u_{n}, u\right) \rightarrow \theta$ and $\left\{u_{n}\right\}$ is a Cauchy sequence if and only if $d\left(u_{n}, u_{m}\right) \rightarrow \theta$ as $n, m \rightarrow+\infty$.

Example 2.1 [24]. Let $E=\mathbb{R}^{2}$ and $P=\left\{v=\left(v_{1}, v_{2}\right) \in E: v_{j} \geq 0\right.$ for $\left.j=1,2\right\}$. Clearly, $P$ is a normal solid cone with normal constant $K=1$. If $X=\mathbb{N}$ and $d(v, v)=$ $(0,0)$ for all $v \in X, d(2,3)=d(3,2)=(5,11)$ and $d(v, u)=(2,4)$ otherwise, then $d$ is a rectangular cone metric on $X$. Clearly, $(X, d)$ is not a cone metric space because it does not satisfy the triangular inequality. Indeed, we have

$$
d(2,3) \preceq d(2,5)+d(5,3) \text { gives that }(5,11) \preceq(2,4)+(2,4) \text { which is not true. }
$$

Lemma 2.6 [24, 37]. Let $E$ be a real Banach space and $P \subset E$ a solid cone. Let $v, w, z \in E$ and $\left\{a_{n}\right\} \subset E$. Then, we have the following properties:

(i) if $z \preceq w$ and $w \ll v$, then $z \ll v$;

(ii) if $\theta \preceq z \ll c$ for each $c \in$ intP then $z=\theta$;

(iii) if $c \in$ intP and $a_{n} \rightarrow \theta$, then there exists $n(c)$, such that for all $n \geq n(c)$, we have $a_{n} \ll c$.

Definition 2.7 [38]. Let $E$ be a topological vector space with a solid cone $P$ and $\left\{u_{n}\right\}$ a sequence in $P$. We say that $\left\{u_{n}\right\}$ is a c-sequence if for every $c \in \operatorname{int} P$, there exist $n(c) \in \mathbb{N}$ such that $u_{n} \ll c$ for all $n \geq n(c)$.

Remark 2.8. Let $(X, d)$ be a rectangular cone metric space over a solid cone, $\left\{u_{n}\right\} \subset X$ and $u \in X$ :

(i) the sequence $\left\{u_{n}\right\}$ converges to $u$ if and only if $\left\{d\left(u_{n}, u\right)\right\}$ is a $c$-sequence;

(ii) if there exist a $c$-sequence $\left\{v_{m}\right\}$ such that $d\left(u_{m}, u_{n}\right) \preceq v_{m}$ for all $m \in \mathbb{N}$ and $n \geq m$, then $\left\{u_{n}\right\}$ is a Cauchy sequence.

The following proposition shows that the notion of $c$-sequence can be given by using $\prec$ or $\preceq$ instead of $\ll$.

Proposition 2.9 [39]. Let $P$ be a solid cone in a topological vector space $E$ and $\left\{u_{n}\right\}$ a sequence in $P$. Then the following conditions are equivalent: 
(i) $\left\{u_{n}\right\}$ is a c-sequence;

(ii) for each $c \gg \theta$, there exists $n(c) \in \mathbb{N}$ such that $u_{n} \prec c$ for $n \geq n(c)$;

(iii) for each $c \gg \theta$, there exists $n(c) \in \mathbb{N}$ such that $u_{n} \preceq c$ for $n \geq n(c)$;

(iv) there exists $c \gg \theta$ such that for any $\lambda \in(0,1)$, there is $n(\lambda) \in \mathbb{N}$ such that $u_{n} \preceq \lambda c$ for all $n \geq n(\lambda)$;

(v) there exists a sequence $\left\{v_{n}\right\}$ such that $v_{n} \gg \theta$ for any $n \in \mathbb{N}, v_{n} \rightarrow \theta$ and for any $n \in \mathbb{N}$, there exists $n(c) \in \mathbb{N}$ such that $v_{m} \preceq v_{n}$ for each $m \geq n(c)$.

Lemma 2.10 [40]. Let $E$ be a real Banach space, $P \subset E$ a cone and $A$ a linear operator on $E$. Then the following conditions are equivalent:

(i) $A$ is nondecreasing, i. e., $u \preceq v$ implies that $A(u) \preceq A(v)$;

(ii) $A$ is positive, i. e., $A(P) \subset P$.

We denote by $M_{n, n}$ the set of all $n \times n$ matrices, and by $M_{n, n}\left(\mathbb{R}^{+}\right)$, we mean the set of all $n \times n$ matrices with nonnegative elements. It is well known that if $A \in M_{n, n}$, then $A(P) \subset P$ if and only if $A \in M_{n, n}\left(\mathbb{R}^{+}\right)$. We write $\Theta$ for the zero $n \times n$ matrix and $I_{n}$ for the identity $n \times n$ matrix. For the sake of simplicity we will identify row and column vector in $\mathbb{R}^{n}$. A matrix $A \in M_{n, n}\left(\mathbb{R}^{+}\right)$is said to be convergent to zero if $A^{n} \rightarrow \ominus$ as $n \rightarrow \infty$.

Following is the extension of Lemma 2.3 in the setting of rectangular cone metric space which can be easily proved.

Lemma 2.11. Let $(X, d)$ be a rectangular cone metric space. Then for each $c \gg 0$, $c \in E$, there exists $\sigma>0$ such that $(c-x) \in \operatorname{int} P($ i.e. $x \ll c)$ whenever $\|x\|<\sigma, x \in E$.

Theorem $2.12[19,20]$. Let $(X, d)$ be a complete generalized metric space, $f: X \longmapsto$ $X$ and $A \in M_{n, n}\left(\mathbb{R}^{+}\right)$a matrix convergent to zero such that $d(f(x), f(y)) \preceq A(d(x, y))$ holds for any $x, y \in X$. Then:

(i) $f$ has a unique fixed point $x^{*} \in X$;

(ii) the sequence of successive approximations $x_{n}=f\left(x_{n-1}\right), n \in \mathbb{N}$ converges to $x^{*}$ for all $x_{0} \in X$;

(iii) $d\left(x_{n}, x^{*}\right) \preceq A^{n}\left(I_{n}-A\right)^{-1}\left(d\left(x_{0}, x_{1}\right)\right), n \in \mathbb{N}$;

(iv) if $g: X \mapsto X$ satisfies the condition $d(f(x), g(x)) \preceq c$ for all $x \in X$ and some $c \in \mathbb{R}^{n}$, then by considering the sequence $y_{n}=g^{n}\left(x_{0}\right), n \in \mathbb{N}$, one has

$$
d\left(y_{n}, x^{*}\right) \preceq\left(I_{n}-A\right)^{-1}(c)+A^{n}\left(I_{n}-A\right)^{-1}\left(d\left(x_{0}, x_{1}\right)\right), n \in \mathbb{N} .
$$

Now we recall some results from Banach algebra theory (see, e.g., [2]). We write $\mathcal{B}(E)$ for the set of all bounded linear operators on $E$ and $\mathcal{L}(E)$ for the set of all linear operators on $E$. Note that $\mathcal{B}(E)$ is a Banach algebra. If $A \in \mathcal{B}(E)$, then

$$
r(A)=\lim \left\|A^{n}\right\|^{\frac{1}{n}}=\inf \left\|A^{n}\right\|^{\frac{1}{n}}
$$


is called the spectral radius of $A$. If $r(A)<1$, then the series $\sum_{i=0}^{+\infty} A^{i}$ is absolutely convergent, consequently, $\left\|A^{n}\right\| \rightarrow 0$ as $n \rightarrow+\infty$. Furthermore, $I-A$ is invertible in $\mathcal{B}(E)$ and

$$
\sum_{n=0}^{+\infty} A^{n}=(I-A)^{-1} .
$$

Moreover, if $\|A\|<1$, then $r(A)<1$ and $I-A$ is invertible and $\left\|(I-A)^{-1}\right\| \leq \frac{1}{1-\|A\|}$ as well as $r\left((I-A)^{-1}\right) \leq \frac{1}{1-r(A)}$. In addition, we have that $(I-A)^{-1}$ is nondecreasing with respect to $P$.

Lemma 2.13 [24]. Let $E$ be a real Banach space and $P \subset E$ a solid cone. If $A \in L(E)$ is nondecreasing, then $A$ is continuous.

Lemma 2.14 [24]. Let $E$ be a real Banach space and $P \subset E$ be a solid cone. Let $A \in L(E)$ be such that $A(P) \subset P$ and $r(A)<1$. Then the following properties hold:

(i) if $a \in P$ is such that $a \preceq A(a)$, then $a=\theta$;

(ii) $r\left(A^{m}\right)<1$ for any fixed $m \in \mathbb{N}$.

Lemma 2.15 [24]. Let $E$ be a real Banach space, $P \subset E$ a solid cone, $A \in L(E)$ a nondecreasing operator and $\left\{u_{n}\right\} \subset P$ a c-sequence. Then, $A\left(u_{n}\right)$ is a c-sequence.

Lemma 2.16 [24]. Let $(X, d)$ be a rectangular cone metric space and $\left\{u_{n}\right\}$ a sequence in $X$ such that

(i) $\left\{d\left(u_{n}, u_{n+1}\right)\right\}$ is a c-sequence;

(ii) $u_{n} \neq u_{m}$ whenever $n \neq m$;

(iii) $u, v \notin\left\{u_{n}: n \in \mathbb{N}\right\}$.

If $\left\{u_{n}\right\}$ converges to both $u$ and $v$, then $u=v$.

Remark 2.17 [33]. Let $P \subseteq E$ be a cone in $E, A: E \rightarrow E$ a linear operator with $r(A)<1$ and $A(P) \subset P$. Then

(a) $(I-A / 2)^{-1} \in \mathcal{B}(E)$. If $B=(I-A / 2)^{-1} A / 2$, then $B \in \mathcal{B}(E), r(B)<r(A)$ and $\|B\| \leq\|A\|$

(b) for any $u, v$ in $P$, we have

$$
u \preceq A\left(\frac{u+v}{2}\right)=\frac{1}{2} A(u)+\frac{1}{2} A(v)
$$

then $u \preceq B(v)$.

Proof of (b) From the assumption we have $(I-A / 2) u \preceq A / 2(v)$, and so $u \preceq B(v)$.

We point out that part (b) is correction of the result Remark 1.16 (b) from [33]. 
Let $(X, d)$ be a rectangular cone metric space. Denote by $P(X)$ the family of all nonempty subsets of $X$, by $P_{c l}(X)$ the family of all nonempty closed subsets of $X$. A point $x$ in $X$ is a fixed point of a multivalued mapping $T: X \rightarrow P(X)$ if $x \in T(x)$. The set of all fixed points of multivalued mapping $T$ is denoted by $\operatorname{Fix}(T)$.

3. Common fixed points of multivalued mappings. We start this section with the following definition of Perov contraction pair.

Definition 3.18. Let $T_{1}, T_{2}: X \rightarrow P_{c l}(X)$ be two multivalued mappings. A pair $\left(T_{1}, T_{2}\right)$ is said to form a Perov contraction pair if there exist a linear bounded operator $A: E \rightarrow E$ with $\|A\|<1$ and $A(P) \subset P$ such that for any $x, y \in X$ with $u_{x} \in T_{i}(x)$, there exists $u_{y} \in T_{j}(y)$ for $i, j \in\{1,2\}$ with $i \neq j$ such that

$$
d\left(u_{x}, u_{y}\right) \preceq A\left(M_{1}\left(x, y, u_{x}, u_{y}\right)\right),
$$

holds, where

$$
M_{1}\left(x, y, u_{x}, u_{y}\right) \in\left\{d(x, y), d\left(x, u_{x}\right), d\left(y, u_{y}\right), \frac{d\left(x, u_{x}\right)+d\left(y, u_{y}\right)}{2}\right\} .
$$

Lemma 3.19. Let $(X, d)$ be a complete rectangular cone metric space over a solid cone $P$ and $T_{1}, T_{2}: X \rightarrow P_{c l}(X)$. If the pair $\left(T_{1}, T_{2}\right)$ is a Perov contraction pair then $\operatorname{Fix}\left(T_{1}\right) \neq \phi$ or $\operatorname{Fix}\left(T_{2}\right) \neq \phi$ if and only if $\operatorname{Fix}\left(T_{1}\right)=\operatorname{Fix}\left(T_{2}\right) \neq \phi$.

Proof. Let $x^{*} \in T_{1}\left(x^{*}\right)$. As, the pair $\left(T_{1}, T_{2}\right)$ forms a Perov contraction pair, there exists $x \in T_{2}\left(x^{*}\right)$ we have

$$
d\left(x^{*}, x\right) \preceq A\left(M_{1}\left(x^{*}, x^{*}, x^{*}, x\right)\right),
$$

where

$$
\begin{aligned}
M_{1}\left(x^{*}, x^{*}, x^{*}, x\right) \in\left\{d\left(x^{*}, x^{*}\right), d\left(x^{*}, x^{*}\right), d\left(x, x^{*}\right),\right. & \left.\frac{d\left(x^{*}, x^{*}\right)+d\left(x, x^{*}\right)}{2}\right\}= \\
& =\left\{d\left(x^{*}, x^{*}\right), d\left(x, x^{*}\right), \frac{d\left(x, x^{*}\right)}{2}\right\} .
\end{aligned}
$$

Now we have three possibilities: if $M_{1}\left(x^{*}, x^{*}, x^{*}, x\right)=d\left(x^{*}, x^{*}\right)=\theta$, then we have $x^{*}=x$, if $M_{1}\left(x^{*}, x^{*}, x^{*}, x\right)=d\left(x, x^{*}\right)$, we have

$$
d\left(x, x^{*}\right) \preceq A\left(d\left(x, x^{*}\right)\right),
$$

by the Lemma 2.14 (i), we have $x^{*}=x$.

If $M_{1}\left(x^{*}, x^{*}, x^{*}, x\right)=\frac{d\left(x^{*}, x\right)}{2}$, then we obtain that $x^{*}=x$. Hence $x^{*} \in T_{2}\left(x^{*}\right)$ and so $\operatorname{Fix}\left(T_{1}\right) \subseteq \operatorname{Fix}\left(T_{2}\right)$. Similarly $\operatorname{Fix}\left(T_{2}\right) \subseteq \operatorname{Fix}\left(T_{1}\right)$ and therefore $\operatorname{Fix}\left(T_{1}\right)=\operatorname{Fix}\left(T_{2}\right)$.

Theorem 3.20. Let $(X, d)$ be a complete rectangular cone metric space over a solid cone $P$. If $T_{1}, T_{2}: X \rightarrow P_{c l}(X)$ forms a Perov contraction pair. Then $\operatorname{Fix}\left(T_{1}\right)=$ $\operatorname{Fix}\left(T_{2}\right) \neq \phi$.

Proof. Suppose that $x_{0}$ is an arbitrary point of $X$. If $x_{0} \in T_{1}\left(x_{0}\right)$ or $x_{0} \in T_{2}\left(x_{0}\right)$, then by Lemma 3.19, the proof is complete. We now assume that $x_{0} \notin T_{i}\left(x_{0}\right)$ for $i \in$ 
$\{1,2\}$. Let $i, j \in\{1,2\}$ with $i \neq j$, and $x_{1} \in T_{i}\left(x_{0}\right)$. As the pair $\left(T_{1}, T_{2}\right)$ is a Perov contraction pair, there exist $x_{2} \in T_{j}\left(x_{1}\right)$ such that

$$
d\left(x_{1}, x_{2}\right) \preceq A\left(M_{1}\left(x_{0}, x_{1}, x_{1}, x_{2}\right)\right),
$$

where

$$
\begin{array}{r}
M_{1}\left(x_{0}, x_{1}, x_{1}, x_{2}\right) \in\left\{d\left(x_{0}, x_{1}\right), d\left(x_{0}, x_{1}\right), d\left(x_{1}, x_{2}\right), \frac{d\left(x_{0}, x_{1}\right)+d\left(x_{1}, x_{2}\right)}{2}\right\}= \\
=\left\{d\left(x_{0}, x_{1}\right), d\left(x_{1}, x_{2}\right), \frac{d\left(x_{0}, x_{1}\right)+d\left(x_{1}, x_{2}\right)}{2}\right\} .
\end{array}
$$

Now, if $M_{1}\left(x_{0}, x_{1}, x_{1}, x_{2}\right)=d\left(x_{0}, x_{1}\right)$, we have $d\left(x_{1}, x_{2}\right) \preceq A\left(d\left(x_{0}, x_{1}\right)\right)$. If $M_{1}\left(x_{0}, x_{1}, x_{1}, x_{2}\right)=d\left(x_{1}, x_{2}\right)$ then $d\left(x_{1}, x_{2}\right) \preceq A\left(d\left(x_{1}, x_{2}\right)\right)$, which by Lemma 2.14 (i) implies that $x_{1}=x_{2}$, that is, $x_{1} \in T_{j}\left(x_{1}\right)$ and hence by the Lemma 3.19, proof is complete. If

$$
M_{1}\left(x_{0}, x_{1}, x_{1}, x_{2}\right)=\frac{d\left(x_{0}, x_{1}\right)+d\left(x_{1}, x_{2}\right)}{2},
$$

then

$$
d\left(x_{1}, x_{2}\right) \preceq \frac{1}{2} A\left(d\left(x_{0}, x_{1}\right)\right)+\frac{1}{2} A\left(d\left(x_{1}, x_{2}\right)\right),
$$

which by Remark 2.17 (b) gives that $d\left(x_{1}, x_{2}\right) \preceq B\left(d\left(x_{0}, x_{1}\right)\right)$.

Let $x_{2} \in T_{j}\left(x_{1}\right)$, there exist $x_{3} \in T_{j}\left(x_{2}\right)$ such that

$$
d\left(x_{2}, x_{3}\right) \preceq A\left(M_{1}\left(x_{1}, x_{2}, x_{2}, x_{3}\right)\right),
$$

where

$$
\begin{aligned}
M_{1}\left(x_{1}, x_{2}, x_{2}, x_{3}\right) \in\left\{d\left(x_{1}, x_{2}\right), d\left(x_{1}, x_{2}\right), d\left(x_{2}, x_{3}\right), \frac{d\left(x_{1}, x_{2}\right)+d\left(x_{2}, x_{3}\right)}{2}\right\}= \\
=\left\{d\left(x_{1}, x_{2}\right), d\left(x_{2}, x_{3}\right), \frac{d\left(x_{1}, x_{2}\right)+d\left(x_{2}, x_{3}\right)}{2}\right\} .
\end{aligned}
$$

Now, if $M_{1}\left(x_{1}, x_{2}, x_{2}, x_{3}\right)=d\left(x_{1}, x_{2}\right)$, we have $d\left(x_{2}, x_{3}\right) \preceq A\left(d\left(x_{1}, x_{2}\right)\right)$. If $M_{1}\left(x_{0}, x_{1}, x_{1}, x_{2}\right)=d\left(x_{2}, x_{3}\right)$ then $d\left(x_{2}, x_{3}\right) \preceq A\left(d\left(x_{2}, x_{3}\right)\right)$, which by Lemma 2.14 (i) implies that $x_{2}=x_{3}$, that is, $x_{2} \in T_{j}\left(x_{2}\right)$ and hence by Lemma 3.19, proof is complete. If

$$
M_{1}\left(x_{0}, x_{1}, x_{1}, x_{2}\right)=\frac{d\left(x_{1}, x_{2}\right)+d\left(x_{2}, x_{3}\right)}{2},
$$

then

$$
d\left(x_{2}, x_{3}\right) \preceq \frac{1}{2} A\left(d\left(x_{1}, x_{2}\right)\right)+\frac{1}{2} A\left(d\left(x_{2}, x_{3}\right)\right),
$$

which by Remark 2.17 (b) implies that $d\left(x_{2}, x_{3}\right) \preceq B\left(d\left(x_{1}, x_{2}\right)\right)$.

Continuing this way, for $x_{2 n} \in T_{j}\left(x_{2 n-1}\right)$, there exist $x_{2 n+1} \in T_{i}\left(x_{2 n}\right)$ such that the following holds:

$$
d\left(x_{2 n}, x_{2 n+1}\right) \preceq A\left(M_{1}\left(x_{2 n-1}, x_{2 n}, x_{2 n}, x_{2 n+1}\right)\right),
$$

where 


$$
\begin{aligned}
& M_{1}\left(x_{2 n-1}, x_{2 n}, x_{2 n}, x_{2 n+1}\right) \in \\
& \in\left\{d\left(x_{2 n-1}, x_{2 n}\right), d\left(x_{2 n-1}, x_{2 n}\right), d\left(x_{2 n}, x_{2 n+1}\right), \frac{d\left(x_{2 n-1}, x_{2 n}\right)+d\left(x_{2 n}, x_{2 n+1}\right)}{2}\right\}= \\
& =\left\{d\left(x_{2 n-1}, x_{2 n}\right), d\left(x_{2 n}, x_{2 n+1}\right), \frac{d\left(x_{2 n-1}, x_{2 n}\right)+d\left(x_{2 n}, x_{2 n+1}\right)}{2}\right\} .
\end{aligned}
$$

If $M_{1}\left(x_{2 n-1}, x_{2 n}, x_{2 n}, x_{2 n+1}\right)=d\left(x_{2 n-1}, x_{2 n}\right)$, then

$$
d\left(x_{2 n}, x_{2 n+1}\right) \preceq A\left(d\left(x_{2 n-1}, x_{2 n}\right)\right) .
$$

For $M_{1}\left(x_{2 n-1}, x_{2 n}, x_{2 n}, x_{2 n+1}\right)=d\left(x_{2 n}, x_{2 n+1}\right)$, we obtain $d\left(x_{2 n}, x_{2 n+1}\right) \preceq$ $A\left(d\left(x_{2 n}, x_{2 n+1}\right)\right)$, which by Lemma 2.14 (i) gives $x_{2 n}=x_{2 n+1}$. Finally, for

$$
M_{1}\left(x_{2 n-1}, x_{2 n}, x_{2 n}, x_{2 n+1}\right)=\frac{d\left(x_{2 n-1}, x_{2 n}\right)+d\left(x_{2 n}, x_{2 n+1}\right)}{2},
$$

we obtain that

$$
\begin{aligned}
d\left(x_{2 n}, x_{2 n+1}\right) \preceq \frac{1}{2} A\left(d\left(x_{2 n-1}, x_{2 n}\right)+d\left(x_{2 n}, x_{2 n+1}\right)\right) & \preceq \\
& \preceq \frac{1}{2} A\left(d\left(x_{2 n-1}, x_{2 n}\right)\right)+\frac{1}{2} A\left(d\left(x_{2 n}, x_{2 n+1}\right)\right)
\end{aligned}
$$

and hence by Remark 2.17 (b) we have

$$
d\left(x_{2 n}, x_{2 n+1}\right) \preceq B\left(d\left(x_{2 n-1}, x_{2 n}\right)\right) .
$$

Similarly, for $x_{2 n+1} \in T_{j}\left(x_{2 n}\right)$, there exist $x_{2 n+2} \in T_{i}\left(x_{2 n+1}\right)$ such that

$$
d\left(x_{2 n+1}, x_{2 n+2}\right) \preceq A\left(d\left(x_{2 n}, x_{2 n+1}\right)\right) \quad \text { or } \quad d\left(x_{2 n+1}, x_{2 n+2}\right) \preceq B\left(d\left(x_{2 n}, x_{2 n+1}\right)\right) .
$$

Therefore, we obtain a sequence $\left\{x_{n}\right\}$ in $X$ such that for $x_{n} \in T_{j}\left(x_{n-1}\right)$, there exist $x_{n+1} \in T_{i}\left(x_{n}\right)$ and it satisfies

$$
d\left(x_{n}, x_{n+1}\right) \preceq A\left(d\left(x_{n-1}, x_{n}\right)\right) \text { for all } n \in \mathbb{N} \quad \text { or } \quad d\left(x_{n}, x_{n+1}\right) \preceq B\left(d\left(x_{n-1}, x_{n}\right)\right) .
$$

First, we prove that $x_{n} \neq x_{m}$ for all $n, m \in \mathbb{N}$ with $n \neq m$. Assume on contrary that there exist $n, p \in \mathbb{N}$ such that $x_{n}=x_{n+p}$ with $p \geq 2$. Then for $x_{n+1}=x_{n+p+1}$, because $A$ and $B$ commute it follows from (3.2) that

$$
d\left(x_{n}, x_{n+1}\right)=d\left(x_{n+p}, x_{n+p+1}\right) \preceq A^{p_{i}} B^{p-p_{i}}\left(d\left(x_{n}, x_{n+1}\right)\right),
$$

where $p_{i} \in\{0,1,2, \ldots, p\}$. Which by the Lemma 2.14 gives that $d\left(x_{n}, x_{n+1}\right)=\theta$ and $x_{n}=x_{n+1}$. Hence, $x_{n} \in T_{i}\left(x_{n}\right)$ for $i \in\{1,2\}$, a contradiction. Thus $x_{n} \neq x_{m}$ for all $n, m \in \mathbb{N}$ with $n \neq m$. Therefore

$$
d\left(x_{n}, x_{n+1}\right) \preceq A^{n_{i}} B^{n-n_{i}}\left(d\left(x_{0}, x_{1}\right)\right),
$$

where $n_{i} \in\{0,1,2, \ldots, n\}$. For $x_{m-2} \in T_{i}\left(x_{m-3}\right)$, there exist $x_{m} \in T_{j}\left(x_{m-1}\right)$ such that

$$
d\left(x_{m-2}, x_{m}\right) \preceq A\left(M_{1}\left(x_{m-3}, x_{m-1}, x_{m-2}, x_{m}\right)\right),
$$


where

$$
\begin{aligned}
& M_{1}\left(x_{m-3}, x_{m-1}, x_{m-2}, x_{m}\right) \in \\
\in & \left\{d\left(x_{m-3}, x_{m-1}\right), \quad d\left(x_{m-3}, x_{m-2}\right), d\left(x_{m-1}, x_{m}\right), \frac{d\left(x_{m-3}, x_{m-2}\right)+d\left(x_{m-1}, x_{m}\right)}{2}\right\} .
\end{aligned}
$$

If $M_{1}\left(x_{m-3}, x_{m-1}, x_{m-2}, x_{m}\right)=d\left(x_{m-3}, x_{m-1}\right)$, then we have

$$
d\left(x_{m-2}, x_{m}\right) \preceq A\left(d\left(x_{m-3}, x_{m-1}\right)\right) \preceq A^{\alpha_{i}} B^{m-2-\alpha_{i}}\left(d\left(x_{0}, x_{2}\right)\right),
$$

where $\alpha_{i} \in\{1,2, \ldots, m-2\}$. If $M_{1}\left(x_{m-3}, x_{m-1}, x_{m-2}, x_{m}\right)=d\left(x_{m-3}, x_{m-2}\right)$, then we obtain that

$$
d\left(x_{m-2}, x_{m}\right) \preceq A\left(d\left(x_{m-3,} x_{m-2}\right)\right) \preceq A^{\beta_{i}} B^{m-2-\beta_{i}}\left(d\left(x_{0}, x_{1}\right)\right),
$$

where $\beta_{i} \in\{1,2, \ldots, m-2\}$. If $M_{1}\left(x_{m-3}, x_{m-1}, x_{m-2}, x_{m}\right)=d\left(x_{m-1}, x_{m}\right)$, then

$$
d\left(x_{m-2}, x_{m}\right) \preceq A\left(d\left(x_{m-1}, x_{m}\right)\right) \preceq A^{\gamma_{i}} B^{m-\gamma_{i}}\left(d\left(x_{0}, x_{1}\right)\right),
$$

where $\gamma_{i} \in\{1,2, \ldots, m-2\}$. Finally, the case

$$
M_{1}\left(x_{m-3}, x_{m-1}, x_{m-2}, x_{m}\right)=\frac{d\left(x_{m-3}, x_{m-2}\right)+d\left(x_{m-1}, x_{m}\right)}{2}
$$

implies that

$$
\begin{aligned}
d\left(x_{m-2}, x_{m}\right) \preceq A( & \left.\frac{d\left(x_{m-3}, x_{m-2}\right)+d\left(x_{m-1}, x_{m}\right)}{2}\right) \preceq \\
& \preceq \frac{1}{2}\left(A\left(d\left(x_{m-3}, x_{m-2}\right)+A\left(d\left(x_{m-1}, x_{m}\right)\right)\right) \preceq\right. \\
& \preceq \frac{1}{2}\left(A^{\delta_{i}} B^{m-2-\delta_{i}}\left(d\left(x_{0}, x_{1}\right)\right)+A^{\eta_{i}} B^{m-\eta_{i}}\left(d\left(x_{0}, x_{1}\right)\right)\right),
\end{aligned}
$$

where $\delta_{i} \in\{1,2, \ldots, m-2\}$ and $\eta_{i} \in\{1,2, \ldots, m\}$. Now for $m, n \in \mathbb{N}$ with $m>n$, we consider the following cases.

If $m-n$ is odd, then by the rectangular inequality, we have

$$
\begin{gathered}
d\left(x_{n}, x_{m}\right) \preceq d\left(x_{n}, x_{n+1}\right)+d\left(x_{n+1}, x_{n+2}\right)+\ldots+d\left(x_{m-1}, x_{m}\right) \preceq \\
\preceq\left[A^{p_{n}} B^{n-p_{n}}+A^{\zeta_{1}} B^{1-\zeta_{1}} A^{p_{n}} B^{n-p_{n}}+\cdots+\right. \\
\left.+A^{\zeta_{1}+\ldots \zeta_{m-1}} B^{m-1-\zeta_{1}-\ldots \zeta_{m-1}} A^{p_{n}} B^{n-p_{n}}\right]\left(d\left(x_{0}, x_{1}\right)\right) \preceq A^{P_{n}} B^{n-p_{n}} W\left(d\left(x_{0}, x_{1}\right)\right) .
\end{gathered}
$$

where $p_{n} \in\{0,1, \ldots, n\}, \zeta_{i} \in\{0,1\}, i=1,2, \ldots, m-1, W=\left(I+\sum_{k=1}^{+\infty} A^{\sigma_{k}} B^{k-\sigma_{k}}\right) \in$ $\mathcal{B}(E), \sigma_{k}=\sum_{i=1}^{k} \zeta_{i}$. Let $c \gg \theta$. Choose $\delta>0$ such that $c+N_{\delta}(\theta) \subseteq P$, where $N_{\delta}(\theta)=$ $\{x \in E:\|x\|<\delta\}$. Also, choose $N_{1} \in \mathbb{N}$ such that $A^{P_{n}} B^{n-p_{n}} W\left(d\left(x_{0}, x_{1}\right)\right) \in N_{\delta}(\theta)$ for all $n>N_{1}$. Thus $\left\{x_{n}\right\}$ is a Cauchy sequence, i. e.,

$$
d\left(x_{n}, x_{m}\right) \preceq A^{P_{n}} B^{n-p_{n}} W\left(d\left(x_{0}, x_{1}\right)\right) \ll c .
$$

If $m-n$ is even, we consider following four cases. 
Case 1. If $M_{1}\left(x_{m-3}, x_{m-1}, x_{m-2}, x_{m}\right)=d\left(x_{m-3}, x_{m-1}\right)$, then by (3.3), we have

$$
d\left(x_{m-2}, x_{m}\right) \preceq A^{\alpha_{i}} B^{m-2-\alpha_{i}}\left(d\left(x_{0}, x_{2}\right)\right),
$$

where $\alpha_{i} \in\{1,2, \ldots, m-2\}$. Also,

$$
\begin{aligned}
d\left(x_{n}, x_{m}\right) \preceq d\left(x_{n}, x_{n+1}\right)+\ldots & +d\left(x_{m-3}, x_{m-2}\right)+d\left(x_{m-2}, x_{m}\right) \preceq \\
& \preceq A^{P_{n}} B^{n-p_{n}} W\left(d\left(x_{0}, x_{1}\right)\right)+A^{\mu_{i}} B^{m-2-\mu_{i}}\left(d\left(x_{0}, x_{2}\right)\right),
\end{aligned}
$$

where $\mu_{i} \in\{1,2, \ldots, m-2\}$.

Case 2. If $M_{1}\left(x_{m-3}, x_{m-1}, x_{m-2}, x_{m}\right)=d\left(x_{m-3}, x_{m-2}\right)$, then by (3.4) we obtain that

$$
d\left(x_{m-2}, x_{m}\right) \preceq A^{\lambda_{i}} B^{m-2-\lambda_{i}}\left(d\left(x_{0}, x_{1}\right)\right),
$$

where $\lambda_{i} \in\{1,2, \ldots, m-2\}$, which implies that

$$
\begin{aligned}
d\left(x_{n}, x_{m}\right) \preceq d\left(x_{n}, x_{n+1}\right)+\ldots & +d\left(x_{m-3}, x_{m-2}\right)+d\left(x_{m-2}, x_{m}\right) \preceq \\
& \preceq A^{p_{n}} B^{n-p_{n}} W\left(d\left(x_{0}, x_{1}\right)\right)+A^{\lambda_{i}} B^{m-2-\lambda_{i}}\left(d\left(x_{0}, x_{1}\right)\right) .
\end{aligned}
$$

Case 3. If $M_{1}\left(x_{m-3}, x_{m-1}, x_{m-2}, x_{m}\right)=d\left(x_{m-1}, x_{m}\right)$, then it follows from $(3.5)$ that

$$
d\left(x_{m-2}, x_{m}\right) \preceq A^{\gamma_{i}} B^{m-\gamma_{i}}\left(d\left(x_{0}, x_{1}\right)\right),
$$

where $\gamma_{i} \in\{1,2, \ldots, m-2\}$. Which gives

$$
\begin{aligned}
d\left(x_{n}, x_{m}\right) \preceq d\left(x_{n}, x_{n+1}\right)+\ldots+ & d\left(x_{m-3}, x_{m-2}\right)+d\left(x_{m-2}, x_{m}\right) \preceq \\
\preceq & A^{p_{n}} B^{n-p_{n}} W\left(d\left(x_{0}, x_{1}\right)\right)+A^{\gamma_{i}} B^{m-\gamma_{i}}\left(d\left(x_{0}, x_{1}\right)\right),
\end{aligned}
$$

where $\gamma_{i} \in\{1,2, \ldots, m-2\}$.

Case 4. If

$$
M_{1}\left(x_{m-3}, x_{m-1}, x_{m-2}, x_{m}\right)=\frac{d\left(x_{m-3}, x_{m-2}\right)+d\left(x_{m-1}, x_{m}\right)}{2},
$$

then by (3.6) we have

$$
d\left(x_{m-2}, x_{m}\right) \preceq 1 / 2\left(A^{\delta_{i}} B^{m-2-\delta_{i}}\left(d\left(x_{0}, x_{1}\right)\right)+A^{\eta_{i}} B^{m-\eta_{i}}\left(d\left(x_{0}, x_{1}\right)\right)\right),
$$

where $\delta_{i} \in\{1,2, \ldots, m-2\}$ and $\eta_{i} \in\{1,2, \ldots, m\}$. And

$$
\begin{aligned}
& d\left(x_{n}, x_{m}\right) \preceq d\left(x_{n}, x_{n+1}\right)+\ldots+d\left(x_{m-3}, x_{m-2}\right)+d\left(x_{m-2}, x_{m}\right) \preceq \\
& \preceq A^{p_{n}} B^{n-p_{n}} W\left(d\left(x_{0}, x_{1}\right)\right)+\frac{1}{2}\left(A^{\delta_{i}} B^{m-2-\delta_{i}}\left(d\left(x_{0}, x_{1}\right)\right)+A^{\eta_{i}} B^{m-\eta_{i}}\left(d\left(x_{0}, x_{1}\right)\right)\right) .
\end{aligned}
$$

Thus in all the cases we obtain that $\left\{x_{n}\right\}$ is a Cauchy sequence as $n, m \rightarrow \infty$. By completeness of $X$, there exist an element $x^{*} \in X$ such that $x_{n} \rightarrow x^{*}$ as $n \rightarrow \infty$.

Let $c \gg \theta$ be given. Choose a natural number $N$ such that $d\left(x_{m}, x^{*}\right) \ll c$ for all $m \geq \mathbb{N}$. As $\left\{x_{2 n}\right\}$ converges to $x^{*}$ as $n \rightarrow \infty$, for $x_{2 n} \in T_{j}\left(x_{2 n-1}\right)$ there exist $u_{n} \in T_{i}\left(x^{*}\right)$ such that

$$
d\left(x_{2 n}, u_{n}\right) \preceq A\left(M_{1}\left(x_{2 n-1}, x^{*}, x_{2 n}, u_{n}\right)\right)
$$


where

$$
\begin{aligned}
& M_{1}\left(x_{2 n-1}, x^{*}, x_{2 n}, u_{n}\right) \in \\
& \quad \in\left\{d\left(x_{2 n-1}, x^{*}\right), \quad d\left(x_{2 n-1}, x_{2 n}\right), d\left(x^{*}, u_{n}\right), \frac{d\left(x_{2 n-1}, x_{2 n}\right)+d\left(x^{*}, u_{n}\right)}{2}\right\} .
\end{aligned}
$$

Note that

$$
\begin{aligned}
d\left(u_{n}, x^{*}\right) \preceq d\left(u_{n}, x_{2 n}\right)+ & d\left(x_{2 n}, x_{2 n+1}\right)+d\left(x_{2 n+1}, x^{*}\right) \preceq \\
& \preceq A\left(M_{1}\left(x_{2 n-1}, x^{*}, x_{2 n}, u_{n}\right)\right)+d\left(x_{2 n}, x_{2 n+1}\right)+d\left(x_{2 n+1}, x^{*}\right) .
\end{aligned}
$$

Now, if $M_{1}\left(x_{2 n-1}, x^{*}, x_{2 n}, u_{n}\right)=d\left(x_{2 n-1}, x^{*}\right)$, then

$$
d\left(u_{n}, x^{*}\right) \preceq A\left(d\left(x_{2 n-1}, x^{*}\right)\right)+d\left(x_{2 n}, x_{2 n+1}\right)+d\left(x_{2 n+1}, x^{*}\right) \ll A(c)+c+c .
$$

As $c \gg 0$ is arbitrary, for $m \geq 1$, we have

$$
d\left(u_{n}, x^{*}\right) \preceq A\left(\frac{c}{m}\right)+\frac{c}{m}+\frac{c}{m}=\frac{A(c)}{m}+\frac{c}{m}+\frac{c}{m} \rightarrow 0
$$

as $m \rightarrow \infty$. If $M_{1}\left(x_{2 n-1}, x^{*}, x_{2 n}, u_{n}\right)=d\left(x_{2 n-1}, x_{2 n}\right)$, then from Lemmas 2.15 and 2.16, we obtain that

$$
d\left(u_{n}, x^{*}\right) \preceq A\left(d\left(x_{2 n-1}, x_{2 n}\right)\right)+d\left(x_{2 n}, x_{2 n+1}\right)+d\left(x_{2 n+1}, x^{*}\right) \ll c+c+c
$$

where $c \gg 0$ is arbitrary. For $m \geq 1$, we have

$$
d\left(u_{n}, x^{*}\right) \preceq \frac{c}{m}+\frac{c}{m}+\frac{c}{m}=\frac{3 c}{m} \rightarrow 0
$$

as $m \rightarrow \infty$. In case $M_{1}\left(x_{2 n-1}, x^{*}, x_{2 n}, u_{n}\right)=d\left(x^{*}, u_{n}\right)$, we have

$$
d\left(u_{n}, x^{*}\right) \preceq A\left(d\left(x^{*}, u_{n}\right)\right)+d\left(x_{2 n}, x_{2 n+1}\right)+d\left(x_{2 n+1}, x^{*}\right)
$$

which gives

$$
(I-A)\left(d\left(u_{n}, x^{*}\right)\right) \preceq d\left(x_{2 n}, x_{2 n+1}\right)+d\left(x_{2 n+1}, x^{*}\right) \preceq 2 c,
$$

where $c \gg 0$ is arbitrary. For $m \geq 1$

$$
d\left(u_{n}, x^{*}\right) \preceq(I-A)^{-1}\left(\frac{c}{m}\right) \preceq \frac{1}{m}(I-A)^{-1}(c) \rightarrow 0
$$

as $m \rightarrow \infty$. Finally, if $M_{1}\left(x_{2 n-1}, x^{*}, x_{2 n}, u_{n}\right)=\frac{d\left(x_{2 n-1}, x_{2 n}\right)+d\left(x^{*}, u_{n}\right)}{2}$, we have

$$
\begin{aligned}
d\left(u_{n}, x^{*}\right) \preceq A & \left(\frac{d\left(x_{2 n-1}, x_{2 n}\right)+d\left(x^{*}, u_{n}\right)}{2}\right)+d\left(x_{2 n}, x_{2 n+1}\right)+d\left(x_{2 n+1}, x^{*}\right) \preceq \\
& \preceq \frac{1}{2} A\left(d\left(x_{2 n-1}, x_{2 n}\right)\right)+\frac{1}{2} A\left(d\left(x^{*}, u_{n}\right)\right)+d\left(x_{2 n}, x_{2 n+1}\right)+d\left(x_{2 n+1}, x^{*}\right) .
\end{aligned}
$$


Therefore,

$$
\left(I-\frac{A}{2}\right) d\left(u_{n}, x^{*}\right) \preceq \frac{1}{2} c+c+c \Longrightarrow d\left(u_{n}, x^{*}\right) \preceq(I-A / 2)^{-1}\left(\frac{c}{2 m}+\frac{c}{m}+\frac{c}{m}\right) \rightarrow 0
$$

as $m \rightarrow \infty$. Thus $u_{n} \rightarrow x^{*}$ as $n \rightarrow \infty$. Since $T_{i}\left(x^{*}\right)$ is closed, $x^{*} \in \operatorname{Fix}\left(T_{j}\right)=\operatorname{Fix}\left(T_{i}\right)$.

Remark 3.21. We notice that the concept of a rectangular cone metric space is more general than one of the rectangular metric space. The results presented in this research article generalized some results of Branciari [3] and Ahmad et al. [4].

Example 3.1. Let $E=\mathbb{R}^{2}, P=\left\{(x, y) \in \mathbb{R}^{2}: x, y \geq 0\right\}$, and $\|x\|=\max \left\{\left|x_{1}\right|,\left|x_{2}\right|\right\}$, where $x=\left(x_{1}, x_{2}\right) \in E$. Suppose that $X=\left\{(x, 0) \in \mathbb{R}^{2}: x \geq 0\right\} \cup\left\{(0, x) \in \mathbb{R}^{2}: x \geq 0\right\}$. Define $d: X \times X \rightarrow E$ by:

$$
\begin{gathered}
d((x, 0),(y, 0))=\left\{\begin{array}{c}
(0,0), \quad \text { if } \quad(x, 0)=(y, 0), \\
(3 \varrho, 3), \text { if } x \text { and } y \text { are in }\{1,2\}, x \neq y, \\
(\varrho, 1), \text { if } x \text { and } y \text { are not in }\{1,2\} \text { simultaneously, } x \neq y, \\
\left(\frac{4}{3}|x-y|,|x-y|\right), \text { otherwise, }
\end{array}\right. \\
d((0, x),(0, y))=\left\{\begin{array}{c}
(0,0), \quad \text { if } \quad(x, 0)=(y, 0), \\
(3 \varrho, 3), \text { if } x \text { and } y \text { are in }\{1,2\}, x \neq y, \\
(\varrho, 1), \text { if } x \text { and } y \text { are not in }\{1,2\} \text { simultaneously, } x \neq y, \\
\left(|x-y|, \frac{2}{3}|x-y|\right), \text { otherwise, }
\end{array}\right.
\end{gathered}
$$

and

$$
d((x, 0),(0, y))=d((0, y),(x, 0))=\left\{\begin{array}{c}
(3 \varrho, 3), \text { if } x \text { and } y \text { are in }\{1,2\}, x \neq y \\
(\varrho, 1), \text { if } x \text { and } y \text { are not both in }\{1,2\}, x \neq y \\
\left(\frac{4}{3} x+y, x+\frac{2}{3} y\right), \text { otherwise }
\end{array}\right.
$$

where $\varrho>0$ is a constant. Note that $(X, d)$ is a complete rectangular cone metric space.

For

$$
\begin{aligned}
&(x, y) \in\{((0,0),(0,0))\} \cup\left\{\left(\left(0, \frac{1}{2}\right),(0,0)\right)\right\} \cup\left\{\left(0, \frac{1}{2}\right),\left(0, \frac{1}{4}\right)\right\} \cup \\
& \cup\left\{\left(\frac{1}{2}, 0\right),(0,0)\right\} \cup\left\{\left(\frac{1}{2}, 0\right),\left(\frac{1}{4}, 0\right)\right\} \cup\{(1,0),(0,2)\},
\end{aligned}
$$

define a mapping $T_{1}, T_{2}: X \rightarrow P_{c l}(X)$ by

$$
T_{1}(x, y)=\left\{\begin{array}{lr}
\{(0, x)\}, & \text { if } y=0 \\
\left\{\left(\frac{x}{2}, 0\right): x \geq 0\right\}, & \text { if } y \neq 0
\end{array}\right.
$$

and

$$
T_{2}(x, y)=\left\{\begin{array}{cc}
\{(0, x)\}, & \text { if } y=0, \\
\left\{\left(\frac{x}{4}, 0\right): x \geq 0\right\}, & \text { if } y \neq 0 .
\end{array}\right.
$$

First, we show that for $x, y \in X$ with $u_{x} \in T_{1}(x)$, there exists $u_{y} \in T_{2}(y)$ such that (3.1) is satisfied. We consider the following cases.

(i) If $x=y=(0,0)$, then (3.1) is satisfied obviously if we take $u_{x}=u_{y}=(0,0)$.

(ii) For $x=\left(0, \frac{1}{2}\right), y=(0,0)$ and $u_{x}=(0,0) \in T_{1}(x)$, take $u_{y}=(0,0) \in T_{2}(y)$. 
(iii) When $x=\left(0, \frac{1}{2}\right), y=\left(0, \frac{1}{4}\right)$ and $u_{x}=(0,0) \in T_{1}(x)$, take $u_{y}=(0,0) \in T_{2}(y)$.

(iv) In case $x=\left(\frac{1}{2}, 0\right), y=(0,0)$ and $u_{x}=\left(0, \frac{1}{2}\right) \in T_{1}(x)$, take $u_{y}=(0,0) \in T_{2}(y)$. Note that

$$
d\left(u_{x}, u_{y}\right)=d\left(\left(0, \frac{1}{2}\right),(0,0)\right)=\left(\frac{1}{2}, \frac{1}{3}\right)
$$

and

$$
d(x, y)=d\left(\left(\frac{1}{2}, 0\right),(0,0)\right)=\left(\frac{2}{3}, \frac{1}{2}\right) .
$$

Now

$$
d\left(u_{x}, u_{y}\right)=\left[\begin{array}{c}
\frac{1}{2} \\
\frac{1}{3}
\end{array}\right]^{t}=\left[\begin{array}{ll}
\frac{3}{4} & 0 \\
0 & \frac{2}{3}
\end{array}\right]\left[\begin{array}{c}
\frac{2}{3} \\
\frac{1}{2}
\end{array}\right]^{t}=A(d(x, y)),
$$

where $d\left(x, u_{x}\right) \in M_{1}\left(x, y, u_{x}, u_{y}\right)$. have

(v) For $x=\left(\frac{1}{2}, 0\right), y=\left(\frac{1}{4}, 0\right)$ and $u_{x}=\left(0, \frac{1}{2}\right) \in T_{1}(x)$, for $u_{y}=\left(0, \frac{1}{4}\right) \in T_{2}(y)$, we

$$
d\left(u_{x}, u_{y}\right)=d\left(\left(0, \frac{1}{2}\right),\left(0, \frac{1}{4}\right)\right)=\left(\frac{1}{4}, \frac{1}{6}\right)
$$

and

$$
d\left(x, u_{x}\right)=d\left(\left(\frac{1}{2}, 0\right),\left(0, \frac{1}{2}\right)\right)=\left(\frac{7}{6}, \frac{5}{6}\right) .
$$

Now

$$
d\left(u_{x}, u_{y}\right)=\left[\begin{array}{c}
\frac{1}{4} \\
\frac{1}{6}
\end{array}\right]^{t} \leq\left[\begin{array}{c}
\frac{7}{8} \\
\frac{5}{9}
\end{array}\right]^{t}=\left[\begin{array}{cc}
\frac{3}{4} & 0 \\
0 & \frac{2}{3}
\end{array}\right]\left[\begin{array}{c}
\frac{7}{6} \\
\frac{5}{6}
\end{array}\right]^{t}=A\left(d\left(x, u_{x}\right)\right)
$$

where $d\left(x, u_{x}\right) \in M_{1}\left(x, y, u_{x}, u_{y}\right)$.

(vi) In case $x=(1,0), y=(0,2)$ and $u_{x}=(0,1) \in T_{1}(x)$, take $u_{y}=(0,0) \in T_{2}(y)$. Note that

$$
d\left(u_{x}, u_{y}\right)=d((0,1),(0,0))=(\varrho, 1), \varrho>0
$$

and

$$
d(x, y)=d((1,0),(0,2))=(3 \varrho, 3), \varrho>0 .
$$

Now

$$
d\left(u_{x}, u_{y}\right)=\left[\begin{array}{l}
\varrho \\
1
\end{array}\right]^{t} \leq\left[\begin{array}{c}
\frac{9 \varrho}{4} \\
2
\end{array}\right]^{t}=\left[\begin{array}{cc}
\frac{3}{4} & 0 \\
0 & \frac{2}{3}
\end{array}\right]\left[\begin{array}{c}
3 \varrho \\
3
\end{array}\right]^{t}=A(d(x, y)),
$$

where $d(x, y) \in M_{1}\left(x, y, u_{x}, u_{y}\right)$.

Now we show that for $x, y \in X$ with $u_{x} \in T_{2}(x)$, there exists $u_{y} \in T_{1}(y)$ such that (3.1) is satisfied. We consider the following cases.

(i) If $x=y=(0,0)$, then (3.1) is satisfied obviously as $u_{x}=u_{y}=(0,0)$.

(ii) For $x=\left(0, \frac{1}{2}\right), y=(0,0)$ and $u_{x}=(0,0) \in T_{2}(x)$, take $u_{y}=(0,0) \in T_{1}(y)$.

(iii) When $x=\left(0, \frac{1}{2}\right), y=\left(0, \frac{1}{4}\right)$ and $u_{x}=(0,0) \in T_{2}(x)$, take $u_{y}=(0,0) \in T_{1}(y)$. and

(iv) In case $x=\left(\frac{1}{2}, 0\right), y=(0,0)$ and $u_{x}=\left(0, \frac{1}{2}\right) \in T_{2}(x)$, take $u_{y}=(0,0) \in T_{1}(y)$,

$$
d\left(u_{x}, u_{y}\right)=d\left(\left(0, \frac{1}{2}\right),(0,0)\right)=\left(\frac{1}{2}, \frac{1}{3}\right),
$$




$$
d\left(x, u_{x}\right)=d\left(\left(\frac{1}{2}, 0\right),\left(0, \frac{1}{2}\right)\right)=\left(\frac{7}{6}, \frac{5}{6}\right) .
$$

Now

$$
d\left(u_{x}, u_{y}\right)=\left[\begin{array}{c}
\frac{1}{2} \\
\frac{1}{3}
\end{array}\right]^{t} \leq\left[\begin{array}{c}
\frac{7}{8} \\
\frac{5}{9}
\end{array}\right]^{t}=\left[\begin{array}{cc}
\frac{3}{4} & 0 \\
0 & \frac{2}{3}
\end{array}\right]\left[\begin{array}{c}
\frac{7}{6} \\
\frac{5}{6}
\end{array}\right]^{t}=A\left(d\left(x, u_{x}\right)\right)
$$

where $d\left(x, u_{x}\right) \in M_{1}\left(x, y, u_{x}, u_{y}\right)$.

(v) For $x=\left(\frac{1}{2}, 0\right), y=\left(\frac{1}{4}, 0\right)$ and $u_{x}=\left(0, \frac{1}{2}\right) \in T_{2}(x)$, take $u_{y}=\left(0, \frac{1}{4}\right) \in T_{1}(y)$. Note that

$$
d\left(u_{x}, u_{y}\right)=d\left(\left(0, \frac{1}{2}\right),\left(0, \frac{1}{4}\right)\right)=\left(\frac{1}{4}, \frac{1}{6}\right)
$$

and

$$
d\left(x, u_{x}\right)=d\left(\left(\frac{1}{2}, 0\right),\left(0, \frac{1}{2}\right)\right)=\left(\frac{7}{6}, \frac{5}{6}\right) .
$$

Also,

$$
d\left(u_{x}, u_{y}\right)=\left[\begin{array}{c}
\frac{1}{4} \\
\frac{1}{6}
\end{array}\right]^{t} \leq\left[\begin{array}{c}
\frac{7}{8} \\
\frac{5}{9}
\end{array}\right]^{t}=\left[\begin{array}{cc}
\frac{3}{4} & 0 \\
0 & \frac{2}{3}
\end{array}\right]\left[\begin{array}{c}
\frac{7}{6} \\
\frac{5}{6}
\end{array}\right]^{t}=A\left(d\left(x, u_{x}\right)\right)
$$

where $d\left(x, u_{x}\right) \in M_{1}\left(x, y, u_{x}, u_{y}\right)$.

Thus the pair $\left(T_{1} \cdot T_{2}\right)$ is forms a Perov contraction with operator $A=\left[\begin{array}{ll}\frac{3}{4} & 0 \\ 0 & \frac{2}{3}\end{array}\right]$. Indeed $A^{n} \rightarrow\left[\begin{array}{ll}0 & 0 \\ 0 & 0\end{array}\right]$ and $\|A\|<1$. So all the conditions of theorem is satisfied. Moreover $(0,0)$ is the fixed point of mappings $T_{1}$ and $T_{2}$.

Our results extend and unify various comparable results in $[24,33]$ and [3]. The next result is a corollary of Theorem 3.20 .

Corollary 3.22. Let $(X, d)$ be a complete metric space, and $T_{1}, T_{2}: X \rightarrow C B(X)$ forms a generalized $R$-mulivalued pair, that is, if for each $x, y \in X, u_{x} \in T_{i} x$, there exists a $u_{y} \in T_{j}$ for each $i, j \in\{1,2\}$ with $i \neq j$ such that

$$
d\left(u_{x}, u_{y}\right) \leq h \max \left\{d(x, y), d\left(x, u_{x}\right), d\left(y, u_{y}\right), \frac{d\left(x, u_{y}\right)+d\left(y, u_{x}\right)}{2}\right\},
$$

where $0 \leq h<1$.

Then $\operatorname{Fix}\left(T_{1}\right)=\operatorname{Fix}\left(T_{2}\right) \neq \emptyset$. Moreover, $\operatorname{Fix}\left(T_{1}\right)=\operatorname{Fix}\left(T_{2}\right)$ is closed.

\section{References}

1. Banach S. Sur les opérations dans les ensembles abstraits et leur applications aux équations integrals. Fund. Math. 3, 133-181 (1922).

2. Malkowsky E., Rakočević V. Advanced Functional Analysis. Boca Raton, FL, CRC Press, Taylor \& Francis Group (2019).

3. Branciari A. A fixed point theorem of Banach - Caccioppoli type on a class of generalized metric spaces. Publ. Math. Debrecen 57, 31-37 (2000).

4. Ahmad J., Arshad M., Vetro C. On a theorem of Khan in a generalized metric space. Int. J. Anal. 2013 (6), 852727 (2013). https://doi.org/10.1155/2013/852727 
5. Kadelburg Z., Radenović S. On generalized metric spaces: A survey. TWMS J. Pure Appl. Math. 5, 3-13 (2014).

6. Kadelburg Z., Radenović S. Fixed point results in generalized metric spaces without Hausdorff property. Math. Sci. 8 (2), 125 (2014). https://doi.org/10.1007/s40096-014-0125-6

7. Karapinar E., Zhang D. Properties and principles in Branciari distance space. J. Fixed Point Theory Appl. 21, 72 (2019). https://doi.org/10.1007/s11784-019-0710-2

8. La Rosa V., Vetro P. Common fixed points for $\alpha-\psi-\varphi$-contractions in generalized metric spaces. Nonlinear Anal. Model. Control 19, 43-54 (2014). https://doi.org/10.15388/NA.2014.1.3

9. Sarma I. R., Rao J. M., Rao S. S. Contractions over generalized metric spaces. J. Nonlinear Sci. Appl. 2, 180-182 (2009). http://dx.doi.org/10.22436/jnsa.002.03.06

10. Vetro C. On Branciari's theorem for weakly compatible mappings. Appl. Math. Lett. 23, 700705 (2010). https://doi.org/10.1016/j.aml.2010.02.011

11. Azam A., Fisher B., Khan M. Common fixed point theorems in complex valued metric spaces. Numer. Funct. Anal. Optim. 32 (3), 243-253 (2011).

12. Filip A.-D., Petrusel A. Fixed point theorems on spaces endowed with vector-valued metrics. Fixed Point Theory Appl. 2010, 281381 (2010). https://doi.org/10.1155/2010/281381

13. Kadelburg Z., Radenović S. Fixed point results in $\mathrm{C}^{*}$-algebra-valued metric spaces are direct consequences of their standard metric counterparts. Fixed Point Theory Appl. 2016, 53 (2016). https://doi.org/10.1186/s13663-016-0544-1

14. Zabreiko P. P. K-metric and K-normed spaces: survey. Collect. Math. 48, 852-859 (1997).

15. Huang L. G., Zhang X. Cone metric spaces and fixed point theorems of contractive mappings. J. Math. Anal. Appl. 332 (2), 1468-1476 (2007). https://doi.org/10.1016/j.jmaa.2005.03.087

16. Jungck G., Radenović S., Radojević S., Rakočević V. Common fixed point theorems for weakly compatible pairs on cone metric spaces. Fixed Point Theory Appl. 2009 (13), 643840 (2009). https://doi.org/10.1155/2009/643840

17. Radenović S. Common fixed points under contractive conditions in cone metric spaces. Comput. Math. Appl. 58, 1273-1278 (2009). https://doi.org/10.1016/j.camwa.2009.07.035

18. Vetro P. Common fixed point in cone metric spaces. Rend. Circ. Mat. Palermo 56, 464-468 (2007). https://doi.org/10.1007/BF03032097

19. Perov A. I. On Cauchy problem for a system of ordinary differential equations. Priblizhennye resheniia differentsial'nykh uravnenii 2, 115-134 (1964). (In Russian)

20. Perov A.I., Kibenko A. V. On a certain general method for investigation of boundary value problem. Izv. Akad. Nauk SSSR Ser. Mat. 30, 249-264 (1966). (In Russian)

21. Azam A., Arshad M., Beg I. Banach contraction principle on cone rectangular metric spaces. Appl. Anal. Discrete Math. 3, 236-241 (2009). https://doi.org/10.2298/AADM0902236A

22. Shukla S., Balasubramanian S., Pavlović M. A Generalized Banach Fixed Point Theorem. Bull. Malays. Math. Sci. Soc. 39, 1529-1539 (2016). https://doi.org/10.1007/s40840-015-0255-5

23. Radenović S., Vetro F. Some Remarks on Perov Type Mappings in Cone Metric Spaces. Mediterr. J. Math. 14, 240 (2017). https://doi.org/10.1007/s00009-017-1039-y

24. Vetro F., Radenović S. Some results of Perov type in rectangular cone metric spaces. J. Fixed Point Theory Appl. 20 (1), 41 (2018). https://doi.org/10.1007/s11784-018-0520-y

25. Markin J. T. Continuous dependence of fixed point sets. Proc. Amer. Math. Soc. 38, 545-547 (1973). https://doi.org/10.1090/S0002-9939-1973-0313897-4

26. Nadler S. B. Multi-valued contraction mappings. Pac. J. Math. 30, 475-488 (1969).

27. Lin L.-J., Wang S.-Yu. Common Fixed Point Theorems for a Finite Family of Discontinuous and Noncommutative Maps. Fixed Point Theory and Applications 2011, 847170 (2011). https://doi.org/10.1155/2011/847170

28. Joseph J. M., Marudai M. Common Fixed Point Theorem for Set-Valued Maps and a Stationary Point Theorem. Int. Journal of Math. Analysis 6 (33), 1615-1621 (2012).

29. Latif A., Beg I. Geometric fixed points for single and multivalued mappings. Demonstr. Math. 30, 791-800 (1997). https://doi.org/10.1515/dema-1997-0410

30. Rus I. A., Petruşel A., Sintămărian A. Data dependence of fixed point set of some multivalued weakly Picard operators. Nonlinear Anal. 52, 1947-1959 (2003). https://doi.org/10.1016/S0362546X(02)00288-2

31. Abbas M., Rhoades B.E. Fixed point theorems for two new classes of multivalued mappings. Appl. Math. Lett. 22, 1364-1368 (2009). https://doi.org/10.1016/j.aml.2009.04.002

32. Altun I., Olgun M. Fixed point results for Perov type F-contractions and an application. J. Fixed Point Theory Appl. 22, 46 (2020). https://doi.org/10.1007/s11784-020-00779-4 
33. Abbas M., Nazir T., Rakočević V. Common Fixed Points Results of Multivalued Perov type Contractions on Cone Metric Spaces with a Directed Graph. Bull. Belg. Math. Soc. Simon Stevin 25 (3), 331-354 (2018). https://doi.org/10.36045/bbms/1536631231

34. Di Bari C., Vetro P. Common fixed points in generalized metric spaces. Appl. Math. Comput. 218, 7322-7325 (2012). https://doi.org/10.1016/j.amc.2012.01.010

35. Rezapour Sh., Hamlbarani R. Some notes on the paper "Cone metric spaces and fixed point theorems of contractive mappings". J. Math. Anal. Appl. 345, 719-724 (2008). https://doi.org/10.1016/j.jmaa.2008.04.049

36. Turkoglu D., Abuloha M. Cone metric Spaces and fixed point theorems in diametrically contractive mappings. Acta Math. Sinica 26, 489-496 (2010). https://doi.org/10.1007/s10114-010-8019-5

37. Zeidler E. Nonlinear Functional Analysis and Its Applications, I: Fixed-Point Theorems. Berlin, Springer (1986).

38. Xu S., Dolićanin C., Radenović S. Some remarks on results of Perov type. J. Adv. Math. Stud. 9 (3), 361-369 (2016).

39. Jachymski J., Klima J. Around Perov's fixed point theorem for mappings on generalized metric spaces. Fixed Point Theory 17 (2), 367-380 (2016).

40. Cvetković M., Rakočević V. Common fixed point results for mappings of Perov type. Math. Nachr. 288 (16), 1873-1890 (2015). https://doi.org/10.1002/mana.201400098

Received: August 27, 2020

Revised: February 26, 2021

Accepted: March 19, 2021

Authors' information:

Mujahid Abbas - Professor, PhD; abbas.mujahid@gmail.com

Vladimir Rakočević - Professor, PhD; vrakoc@sbb.rs

Zahra Noor — znoor2175@gmail.com

\title{
Многозначная сжимающая пара Перова в метрических пространствах прямоугольного конуса
}

\author{
M. Аббас ${ }^{1,2}$, В. Ракочевич ${ }^{3}$, 3. Нyр ${ }^{1}$ \\ 1 Государственный колледж Университета Лахора, Лахор, 54000, Пакистан \\ 2 Университет Претории, Претория, 0002, Южная Африка \\ 3 Университет Ниша, Ниш, 18000, Сербия
}

Для цитирования: Abbas M., Rakočević V., Noor Z. Perov multivalued contraction pair in rectangular cone metric spaces // Вестник Санкт-Петербургского университета. Математика. Механика. Астрономия. 2021. Т. 8 (66). Вып. 3. С. 484-501.

https://doi.org/10.21638/spbu01.2021.310

Перов изучил принцип Банахова сжатия в рамках обобщенного метрического пространства и представил условие сжатия, при котором сжимающая постоянная заменяется матрицей с неотрицательными входами и спектральным радиусом менее 1. Азам и др. представили понятие прямоугольного конусного метрического пространства, следуя идее Бранчиари, Хуана и Чжана, заменив треугольное неравенство в конусном метрическом пространстве прямоугольным неравенством. Мотивированная работой Аббаса, Ветро и Раденовича цель настоящей работы состоит в том, чтобы ввести новый класс многозначных отображений типа Перова и представить общий результат фиксированной точки для таких отображений на полном метрическом пространстве прямоугольного конуса. В работе приведен пример, демонстрирующий справедливость 
полученных результатов. Наши выводы расширяют, объединяют и обобщают различные сопоставимые результаты в существующей литературе.

Ключевые слова: неподвижная точка, коническое метрическое пространство, прямоугольное метрическое пространство.

Статья поступила в редакцию 27 августа 2020 г.; после доработки 26 февраля 2021 г.; рекомендована в печать 19 марта 2021 г.

Контактная информация:

Аббас Моджахед — abbas.mujahid@gmail.com

Ракочевич Владимир - vrakoc@sbb.rs

Hур Захра - znoor2175@gmail.com 